ZOOLOGIA 30 (2): 125-129, April, 2013

http://dx.doi.org/10.1590/S1984-46702013000200001

\title{
The effect of increased light intensity on the aggressive behavior of the Nile tilapia, Oreochromis niloticus (Teleostei: Cichlidae)
}

\author{
Thaís B. Carvalho', Francine Z. Mendonça ${ }^{2}$, Roselene S. Costa-Ferreira ${ }^{2} \&$ \\ Eliane Gonçalves-de-Freitas ${ }^{2,3}$
}

\author{
${ }^{1}$ Departamento de Ciências Fisiológicas, Universidade Federal do Amazonas. Avenida General Rodrigo Octávio Jordão Ramos \\ 3000, 69077-000 Manaus, AM, Brazil. \\ ${ }^{2}$ Departamento de Zoologia e Botânica, IBILCE, Centro de Aquicultura, Universidade Estadual Paulista. Rua Cristóvão \\ Colombo 2265, 15054-000 São José do Rio Preto, SP, Brazil. \\ ${ }^{3}$ Corresponding author. E-mail: elianeg@ibilce.unesp.br
}

\begin{abstract}
Animals show behavioral and physiological changes that emerge in response to environmental perturbations (i.e., emergency life-history stages). In this study, we investigate the effects of light intensity on aggressive encounters and social stability in groups of adult male Nile tilapia, Oreochromis niloticus (Linnaeus, 1758). The study compared the behavior observed under low $(280.75 \pm 50.60 \mathrm{~lx})$ and high $(1394.14 \pm 520.32 \mathrm{~lx})$ light intensities, with 12 replicates for each treatment. Adult fish were isolated in 36-L aquaria for 96 hours, and three males were grouped for 11 days in $140-\mathrm{L}$ aquaria. Agonistic behavior was video-recorded (10 min/day) on the $3^{\text {rd }}, 5^{\text {th }}, 7^{\text {th }}$, and $9^{\text {th }}$ day to quantify aggressive interactions and social stability. There was an effect of light intensity and day of observation on the total number of agonistic behaviors performed by the fish group. Besides, increased frequency of aggressive interactions (the sum of the four sessions) by the alpha, beta and gamma fish occurred at the higher light intensity. The dominance ranks of the fish remained unchanged across the observation sessions under both the low and high light intensities. We concluded that enhanced light intensity has a cumulative effect that increases the aggressiveness of the Nile tilapia but that this effect is not sufficiently strong to destabilize the social hierarchy.
\end{abstract}

KEY WORDS. Aggressiveness; aquaculture; environmental changes; social rank.

Factors producing long-term modifications to the aquatic environment can emerge from global climate perturbations, destruction of riparian vegetation, and the artificial environments found in aquaculture systems (BARRELLA et al. 2000). Changes in abiotic factors, such as water temperature, water level, photoperiod, and light intensity, can affect the physiology and behavior of teleosts (e.g., Britz \& Pienaar 1992, AlmazÁn-Rueda et al. 2005, EL-SAYED \& KAWANNA 2007).

Light intensity is one of several abiotic variables that affect fish aggressive behavior (SAKakURa \& Tsukamoto 1997, Valdimarsson \& Metcalfe 2001, Almazán-Rueda et al. 2004, Castro $\&$ CABALLERo 2004). Because this effect can interfere with the stability of the dominance hierarchy, understanding fish response to light intensity is important if specimens are reared artificially (BALdisSERotTo 2002). Some indirect effects of light intensity on the social hierarchy have previously been observed in fish. For instance, the hormone melatonin, the levels of which are reduced by high light intensity (ЕкsтRÖм \& MeIssL 1997), can control the physiological and behavioral profile of subordinate rainbow trout. According to LARSON et al. (2004), low melatonin can reduce the signals produced by the subordinate fish and, in turn, destabilize the social hierarchy. Thus, we hypothesize that increased light intensity increases aggression and disrupts social stability in groups of the Nile tilapia, Oreochromis niloticus (Linnaeus, 1758). This hypothesis is based on the findings that the melatonin levels of Nile tilapia are reduced during photophase (Martinez-Chavez et al. 2008), and that reductions in this hormone increase aggressiveness in another cichlid species, Aequidens pulcher (Gill, 1858) (MunRo 1986) and thereby produce social destabilization (e.g. Boscolo et al. 2011).

Although the social hierarchy is modulated by several factors related to aggressive motivation (Nelissen \& ANDries 1988, Quinn et al. 1996, CarvalHo \& Gonçalves-De-Freitas 2008), studies linking changes in environmental factors to the dominance hierarchy are scarce in fish. A number of previous studies have considered the availability of shelters (KADRY \& BARRETO 2010), the physical structure of the environment (HofMANn et al. 1999), the concentration of oxygen (SNEDDON \& YeRBURY 2004), and the water level and flow (Sloman et al. 2001, SNEDdon et al. 2006, GonçALVESDE-Freitas et al. 2008). However, the effect of light intensity on the stability of the social hierarchy has been investigated to a lesser extent, primarily in cichlids. 
The Nile tilapia is one of the primary species reared in aquaculture worldwide (Popma \& Lovshin 1995). As a cichlid, the Nile tilapia is territorial and exhibits a social hierarchy established by aggressive interactions (GonçALVES-DE-Freitas et al. 2008, Carvalho \& Gonçalves-De-Freitas 2008). Social dominance relationships can increase social stress as a result of increased aggressive interactions (ZAYAN 1991). Moreover, the luminosity interferes with reproduction, growth, metabolic rate, aggressiveness in the Nile tilapia (BISWAS \& TAKEUCHI 2002, Biswas et al. 2005, 2006, CARvalHo et al. 2012), and this may affect the social hierarchy. Thus, we tested the effect of light intensity on the aggressiveness and social hierarchy in a cichlid fish, $O$. niloticus. Such studies can contribute to the scientific understanding of the mechanisms controlling aggressiveness in fish.

\section{MATERIAL AND METHODS}

The fish were initially kept in a fish pond (a $185-\mathrm{m}^{3}$ tank). Prior to the beginning of the study, the specimens were transferred to the laboratory and kept there for 15 days before experimentation in 500-L indoor tanks (ca.1 fish/5 L) with no chlorinated water, a temperature of approximately $27^{\circ} \mathrm{C}$, controlled light intensity $(749.8 \pm 89.7 \mathrm{~lx})$ and 12 -hours light/dark cycles. Biological filters were used to guarantee water quality. The fish were fed commercial tropical fish food (28\% of crude protein, Guabi/Pirá, Campinas, Brazil) twice a day.

Seventy-two adult male Nile tilapias were exposed to low $(280.75 \pm 50.60 \mathrm{~lx})$ or high $(1394.14 \pm 520.32 \mathrm{~lx})$ light intensity treatments. The fish were initially isolated for 96 hours in each light treatment to reduce the effect of previous social experience (during rearing) on aggressive behavior. Thereafter, three individuals were grouped in another aquarium for 11 days under each treatment, and their agonistic behavior was videorecorded (10 $\mathrm{min} /$ day at the $3^{\text {rd }}, 5^{\text {th }}, 7^{\text {th }}$, and $9^{\text {th }}$ day) to quantify agonistic interactions and the stability of the hierarchy. Twelve replicates were used for each treatment.

Animals were weighed, measured and sexed for grouping. The groups were formed using animals with similar standard length (one-way ANOVA, low light: $\mathrm{df}=2, \mathrm{~F}=0.02, \mathrm{p}=0.98$; high light: $\mathrm{df}=2, \mathrm{~F}=0.03, \mathrm{p}=0.97$ ) and body weight (one-way ANOVA, low light: $\mathrm{df}=2, \mathrm{~F}=0.12, \mathrm{p}=0.89$; high light: $\mathrm{df}=2$, $\mathrm{F}=0.39, \mathrm{p}=0.68$ ) because size is a factor that affects agonistic behavior (BEeching 1992). The animals were identified by different cuts in the tail fin (FERNANdes \& Volpato 1993, Höglund et al. 2005). Sexing was performed by staining the genital papillae with methylene blue to reveal the opening of the oviduct in females (e.g., Carvalho \& Gonçalves-de-Freitas 2008).

We used $40 \mathrm{~cm} \times 30 \mathrm{~cm} \times 40 \mathrm{~cm}$ (ca. $36 \mathrm{~L}$ ) glass aquaria for isolation and $60 \mathrm{~cm} \mathrm{x} 60 \mathrm{~cm} \mathrm{x} 40 \mathrm{~cm}$ (ca. $140 \mathrm{~L}$ ) glass aquaria for 3-male groups. Three walls of the aquarium were covered with opaque blue plastic to prevent visual contact between neighboring fish. The blue color was chosen because of its tendency to reduce cortisol levels in Nile tilapia (Volpato \& BARRETo
2001). The high light intensity used in the experiment was produced by four $9 \mathrm{~W}$ fluorescent light bulbs placed $55 \mathrm{~mm}$ above the surface of the water. The low light intensity was obtained from the standard illumination of the laboratory (four $40 \mathrm{~W}$ fluorescent light bulbs). Because the light intensity inside the aquarium can vary from the surface to the bottom and from the center to the sides, we divided the aquaria into 36 quadrants (three layers of 12 squares, each $9.0 \times 9.0 \times 9.0 \mathrm{~cm}$ ) and recorded the light intensity at each point with a portable digital luximeter (model LD 240). The average light intensities inside the aquaria were then used as the representative values for the low and high intensity treatments.

Individual biological filters and constant aeration were provided for each aquarium. The $\mathrm{pH}$ was set at 7.2 and the ammonia level at $0.25 \mathrm{ppm}$. Water temperature was $26.38 \pm 0.67^{\circ} \mathrm{C}$, and the photoperiod was a 12 hours light/dark cycle, starting at 0700 . Feed pellets (commercial food for tropical fish, $28 \%$ of crude protein, corresponding to $2 \%$ of biomass) were offered twice a day.

Fish manipulation (size measurement, weighing, cutting the tail fin and transferring fish from one aquarium to another) was always preceded by anesthesia with benzocaine $(3 \mathrm{mg} / \mathrm{L})$. At the end of the experiment, the fish were euthanized by a lethal dose of anesthetic (benzocaine: $27 \mathrm{mg} / \mathrm{L}$ ) and dissected for gonad inspection and confirmation of sex and sexual maturity. Gonad maturation was assessed by macroscopic inspection. The morphological descriptions for the Nile tilapia in Babiker \& Ibrahim (1979) were used.

We quantified agonistic interaction, based on the ethogram described for Nile tilapia in FALTER (1983), as circling, chase, lateral fight, mouth fight, nipping, threat and undulation. We calculated the total amount of fighting behavior as the sum of all agonistic events. Aggressive acts were considered for each animal, and rank was defined by a dominance index (DI = given attacks/given + received attacks) as used by Oliveira \& Almada (1996) for other cichlid species. DI varies from 0 to 1.0. Social position was classified according to the decreasing sequence of DI values as alpha (dominant), beta (intermediate) and gamma (subordinate). These ranks were determined within the group for each observation session.

The Shapiro-Wilk's test was used to assess data normality (ZAR 1999) and F max was used to assess homoscedasticity $\left(\mathrm{H}_{\mathrm{A}} \& \mathrm{HA}_{\mathrm{A}} 2011\right)$ after square root transformation of data. We compared the total amount of fighting behavior over time (four observation sessions) and light-intensity conditions with a mixed-model ANOVA followed by Fisher LSD post hoc test, with the light-intensity treatment as the independent factor and the observation session as a repeated measure. Complementarily, we compare the total frequency of aggression (the sum of aggressive acts performed during the four sessions) between treatments and ranks by two-way ANOVA, being the light intensity the independent variable and ranks, the dependent one. The persistence of individual rank over sessions in each light-intensity condition (social stability) was tested with Kendall's 
coefficient of concordance (e.g., GómEz-Laplaza \& Morgan 1993). The statistical significance level was set at $\alpha=0.05$.

This study was conducted according to the ethical principles adopted by the Brazilian College of Animal Experimentation (COBEA) and was approved by the Ethical Committee of Animal Experimentation of the São Paulo State University (UNESP), Botucatu, SP, Brazil (protocol 52/06).

\section{RESULTS}

The Mixed-model ANOVA showed significant effect of the light intensity ( $\mathrm{df}=1, \mathrm{~F}=4.69, \mathrm{p}=0.04)$ and observation sessions $(\mathrm{df}=3, \mathrm{~F}=4.10, \mathrm{p}=0.01)$ on the total amount of aggression for the whole group. The two first session were similar between them (LSD, $p=0.66$ ), but significant different from the last two observations (LSD, $\mathrm{p}<0.04$ ). The last two were not statistically different (LSD, p = 0.73) (Fig. 1). There was no significant interaction between light intensity and observation sessions $(\mathrm{df}=3, \mathrm{~F}=$ $1.96, \mathrm{p}=0.13$ ). Complementarily, the analysis of total aggression by rank order, also showed a significant effect of the light intensity (2-way ANOVA, df = 1, F = 10.96, p = 0.0015), and rank ( $\mathrm{df}=$ $2, \mathrm{~F}=346.36, \mathrm{p}=0.000001)$. In this case, alpha, beta and gamma were all different among them (LSD, $\mathrm{p}<0.000001$ ) (Fig. 2). There was no significant interaction between light intensity and rank of fish ( $\mathrm{df}=2, \mathrm{~F}=0.46, \mathrm{p}=0.63$ ). A significant rank-order agreement over days was found for all groups tested, both at the low and at the high light intensities (Kendall's coefficient of concordance; low: $\mathrm{W}<0.25, \mathrm{p}>0.28$; high: $\mathrm{W}<0.22$, $\mathrm{p}>0.34$ ).

\section{DISCUSSION}

The results of this study have demonstrated that aggressive behavior in groups of Nile tilapia was increased by high light intensity, but that this effect did not destabilize rank order. Moreover, the effect was widespread in the social group, regardless of social rank. According to Martinez-Chavez et al. (2008), melatonin in the Nile tilapia is controlled by the light regimen. This is a possible mechanism modulating aggressive behavior in this species, as Melatonin levels increase under low light- conditions (Eкström \& MeIssL 1997, BayarRi et al. 2002) and can reduce aggression in cichlids (MunRo 1986). Moreover, high levels of melatonin induce subordination in rainbow trout (LARson et al. 2004). This behavioral modulation, however, contrasts with observations on the fish life stage. CarvalHo et al. (2012) found that juvenile Nile tilapias have less motivation to fight under conditions of intense light. It is possible that juveniles are less aggressive when light is intense because they need to reduce predation risk, whereas adults need to defend their territory and attract females under those conditions (CarvalHo et al. 2008). Studies on the behavior of the different life stages and the effect of melatonin on fish aggressive behavior, however, are rare in the literature.

High levels of aggressive interaction can harm fish health and welfare in aquaculture systems because more intense and

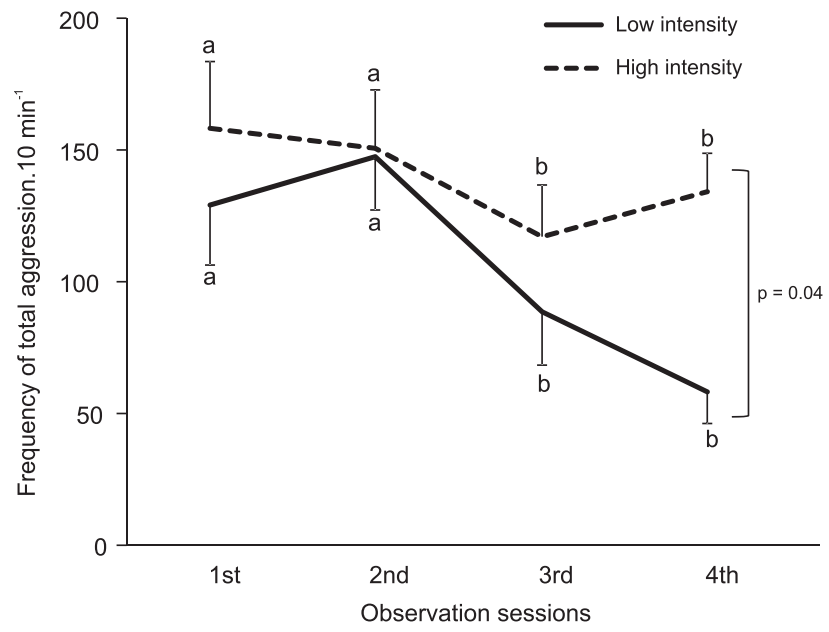

Figure 1. Mean ( $\pm \mathrm{SE}$ ) frequency of the total aggression of the whole group ( 3 fish) showed by session of observation. Letters compare observation sessions (repeated measures) and the lateral bar compares the light intensity. Different letters means significant difference (mixed model ANOVA, completed with Fisher LSD test).

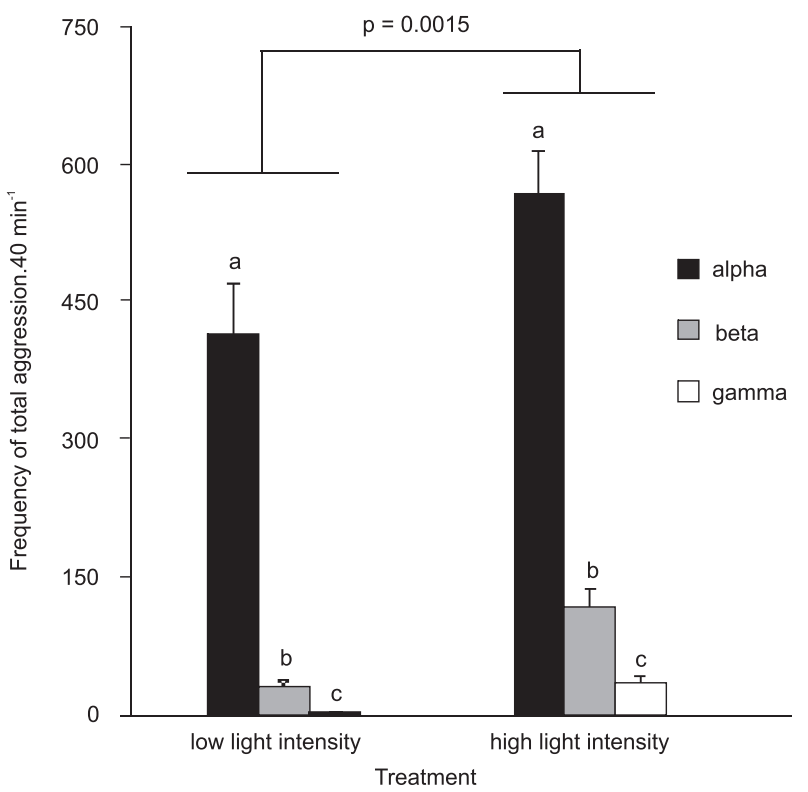

Figure 2. Mean ( $\pm \mathrm{SE}$ ) frequency of the total aggression of the whole period (sum of the 4 observation sessions) by hierarchical rank. Letters compare ranks and the upper bar compares the light intensity. Different letters means significant difference (2-way ANOVA, completed with Fisher LSD test).

prolonged contests produce a well-documented impact on energy expenditure and the risk of injuries to the contestants (e.g., JoHnsson et al. 2006). Accordingly, the manipulation of light 
intensity can represent an approach to reducing aggressiveness in the artificial rearing of social fish, such as the Nile tilapia.

We expected that the high aggressiveness produced by high light intensity would destabilize the social hierarchy of the groups. In fact, several biotic and abiotic factors affect the aggressive interaction and dominance hierarchy, for instance, the same-sized fish group (Boscolo et al. 2011), the sex group composition (CARVAlHo \& Gonçalves-de-Freitas 2011), the availability of shelters (KADRY \& BARRETO 2010), the concentration of oxygen (SNeddon \& Yerbury 2004), and the water level (Gonçalves-De-Freitas et al. 2008). However, the effect of light intensity on the aggressive behavior was not sufficient to make the hierarchy unstable. Thus, the social challenges occurring among the alpha, beta, and gamma fish seem to be similar in the groups exposed to low and high light intensities.

Our result represents a component of the emergency lifehistory stage "take-it-or-leave-it", which corresponds to the behavioral and physiological strategies used by organisms to adjust to long-term perturbations of the physical environment. According to WINGFIELD (2003), vertebrates have evolved behavioral and physiological strategies to avoid the potential deleterious effects of predictable or unpredictable events. In this sense, the effect of light intensity on agonistic interactions indicates that fish change their behavior in response to abiotic perturbations. In Nile tilapia, this strategy is marked by an increase in aggressive interactions that maintains the social ranks in the group.

High light intensity has a cumulative effect on the aggressiveness of male Nile tilapia, but it is not sufficient to affect social stability. Therefore, light intensity is a factor that modulates aggressive behavior, and ambient light variation is a labile perturbation that can trigger emergency behavioral strategies in cichlid fish. Environmental factors should be controlled in aquaculture systems, and this finding can be considered in the design and management of rearing systems to minimize the undesirable effects of fighting on fish health and welfare.

\section{ACKNOWLEDGMENTS}

The authors thank Carlos E. Souza for technical support. This study was sponsored by Fundação de Amparo à Pesquisa do Estado de São Paulo (FAPESP, proc. 2006/05013-0).

\section{LITERATURE CITED}

Almazán-Rueda, P.; A.T.M. Van-Helmond; J.A.J. Verreth \& J.W. Schrama. 2005. Photoperiod affects growth, behaviour and stress variables in Clarias gariepinus. Journal of Fish Biology 67 (4): 1029-1039. doi:10.1111/j.0022-1112.2005.00806.x.

Almazán-Rueda, P.; J.W. Schrama \& J.A.J. Verreth. 2004. Behavioural responses under different feeding methods and light regimes of the African catfish (Clarias gariepinus) juveniles. Aquaculture 231 (1-4): 347-359. doi:10.1016/ j.aquaculture.2003.11.016.
BabiKer, M.M. \& H. Ibrahim. 1979. Studies on the biology of reproduction in the cichlid Tilapia nilotica (L.): gonadal maturation and fecundity. Journal of Fish Biology 14 (5): 437-448. doi:10.1111/j.1095-8649.1979.tb03541.x.

Baldisserotto, B. 2002. Fisiologia de Peixes Aplicada à Piscicultura. Santa Maria, Editora UFSM.

Barrella, W.; M. Petrere Jr; W.S. Smith \& L.F.A. Montag. 2000. As relações entre as matas ciliares, os rios e os peixes, p. 187207. In: R.R. Rodrigues \& F.L.H. Filho (Ed.). Matas Ciliares: conservação e recuperação. São Paulo, EDUSP, FAPESP.

Bayarri M.J.; J.A. Madrid \& F.J. SÁnchez-VÁZquez. 2002. Influence of light intensity, spectrum and orientation on sea bass plasma and ocular melatonin. Journal of Pineal Research 32 (1): 34-40. doi: 10.1034/j.1600-079x.2002.10806.x.

BEeCHING, S.C. 1992. Visual assessment of relative body size in a cichlid fish, the oscar, Astronotus ocellatus. Ethology 90 (3): 177-186. doi:10.1111/j.1439-0310.1992.tb00831.x.

BisWAS A.K. \& T. TAKEUCHI. 2002. Effect of different photoperiod cycles on metabolic rate and energy loss of fed and unfed adult Oreochromis niloticus: Part II. Fisheries Science 68 (3): 543-553. doi: 10.1046/j.1444-2906.2002.00460.x.

Biswas A.K.; T. Morita; G. Yoshizaki; M. Maita \& T. Takeuchi. 2005. Control of reproduction in Nile tilapia Oreochromis niloticus by photoperiod manipulation. Aquaculture 243 (1-4): 229239. doi:.org/10.1016/j.aquaculture.2004.10.008.

Biswas A.K.; M. SEOKa; Y. TanaKa; K. TaKII \& H. Kumai. 2006. Effect of photoperiod manipulation on the growth performance and stress response of juvenile red sea bream (Pagrus major). Aquaculture 258: 350-356. doi:10.1016/j.aquaculture.2006.03.048.

Boscolo, C.N.P.; R.N. Morais \& E. GonÇALVES-DE-Freitas. 2011. Samesized fish groups increase aggressive interaction of sex-reversed males Nile tilapia GIFT strain. Applied Animal Behaviour Science 135: 154-159. doi:10.1016/j.applanim.2011.10.003.

Britz, P.J. \& A.G. PienaAr. 1992. Laboratory experiments on the effect of light and cover on the behaviour and growth of African catfish, Clarias gariepinus (Pisces: Clariidae). Journal of Zoology 227 (1): 43-62. doi:10.1111/j.1469-7998.1992.tb04343.x.

Carvalho, T.B. \& E. Gonçalves-de-Freitas. 2008. Sex group composition, social interaction, and metabolism in the fish Nile tilapia. Brazilian Journal of Biology 68 (4): 807-812. doi:10.1590/S1519-69842008000400015.

Carvalho, T.B. \& E. Gonçalves-de-Freitas. 2011. Social stability related to sex group composition in cichlid Nile tilapia. Dynamic Biochemistry Process Biotechnology and Molecular Biology 5 (1): 88-91.

CarvalHo T.B.; J.C. Ha \& E. GonÇalves-DE-Freitas. 2012. Light intensity can trigger different agonistic responses in juveniles of three cichlid species. Marine and Freshwater Behaviour and Physiology 45 (2): 91-100. doi:10.1080/10236244.2012.690564.

Castro, J.J. \& C. Caballero. 2004. Effect of the light intensity upon the agonistic behaviour of juvenile of white-seabream (Diplodus sargus cadenati de La Paz, Bauchot and Daget, 1974). Aggressive Behaviour 30 (4): 313-318. doi:10.1002/ab.20023. 
Eкström, P. \& H. MeissL. 1997. The pineal organ of teleost fishes. Reviews in Fish Biology and Fisheries 7 (2): 199-284. doi:10.1023/A:1018483627058.

EL-SAYED, A.F.M. \& M. KaWANNA. 2007. Effects of photoperiod on growth and spawning efficiency of Nile tilapia (Oreochromis niloticus L.) broodstock in a recycling system. Aquaculture Research 38 (12): 1242-1247. doi:10.1111/j.1365-2109. 2007.01690.x.

FaLTER, U. 1983. Les comportaments agonistiques de Sarotherodon niloticus (Pisces, Cichlidae) et la signification évolutive de l'incubation buccale. Bulletin de La Classe Des Sciences Academie Royale de Belgique 69: 566-593.

Fernandes, M.O \& G.L. Volpato. 1993. Heterogeneous growth in the Nile tilapia: social stress and carbohydrate metabolism. Physiology and Behaviour 54 (2): 319-323. doi: 10.1016/0031-9384(93)90117-X.

Goméz-Laplaza, L.M. \& E. Morgan. 1993. Social isolation, aggression, and dominance in attacks in juvenile angelfish, Pterophyllum scalare. Aggressive Behaviour 19 (3): 213-222. doi: 10.1002/1098-2337.

Gonçalves-de-Freitas, E.; F.B. Teresa; F.S. Gomes \& P.C. Giaquinto. 2008. Effect of water renewal on dominance hierarchy of juvenile Nile tilapia. Applied Animal Behaviour Science 112 (1): 187-195. doi:10.1016/j.applanim.2007.07.002.

$H_{A}$, R.R. \& J.C. HA. 2011. Integrative statistics for the social and behavioral sciences. Thousand Oaks, Sage Publishing.

Hofmann, H.A.; M.E. Benson \& R.D. Fernald. 1999. Social status regulates growth rate: consequences for life-history strategies. Proceedings of the National Academic of Science 96 (24): 14171-14176. doi:10.1073/pnas.96.24.14171.

Höglund, E.; M.J. BakKeb; O. ØverLi; S. Winberg \& G.E. NiLSSON. 2005. Suppression of aggressive behaviour in juvenile Atlantic cod (Gadus morhua) by l-tryptophan supplementation. Aquaculture 249 (1-4): 525-531. doi:10.1016/j.aquaculture.2005.04.028.

Johnsson, J.I.; S. Winberg. \& K.A. SLOMAN. 2006. Social interactions, p. 151-196. In: K.A. Sloman; R.W. Wilson \& S. Balshine (Eds). Behaviour and physiology of fish. San Diego, Elsevier.

KADRY, V.O. \& R.A. BARRETO. 2010. Environmental enrichment reduces aggression of pearl cichlid, Geophagus brasiliensis, during residentintruder interactions. Neotropical Ichthyology 8 (2): 329-332. doi:10.1590/S1679-62252010000200011.

Larson, E.T.; S. Winberg; I. Mayer; O. Lepage; C.H. Summers \& O. OverLI. 2004. Social stress affects circulating melatonin levels in rainbow trout. General and Comparative Endocrinology 136 (3): 322-327. doi:10.1016/j.ygcen.2004.01.005.

Martinez-Chavez, C.C.; S. Sammi Al Khamees; A. Campos Mendoza; D.J. Penman \& H. Migaud. 2008. Clock controlled endogenous melatonin rhythms in Nile tilapia (Oreochromis niloticus niloticus) and African catfish (Clarias gariepinus). Chronobiology International 25 (1): 31-49. doi:10.1080/07420520801917547.

Munro, A.D. 1986. Effects of melatonin, serotonin, and naloxone on aggression in isolated cichlid fish (Aequidens pulcher). Journal of Pineal Research 3 (3): 257-262. PMID: 3772724.
Nelissen, M.H.J. \& S. Andries. 1988. Does previous experience affect the ranking of cichlid fish in a dominance hierarchy? Annalles de la Societe Royale Zoologique de Belgique 118: 41-50.

Oliveira, R.F. \& V.C. Almada. 1996. Dominance hierarchies and social structure in captive groups of the Mozambique tilapia Oreochromis mossambicus (Teleostei Cichlidae). Ethology, Ecology and Evolution 8 (1): 39-55.

Popma, T.J. \& L.L. Lovshin. 1995. Worldwide prospects for commercial production of tilapia. Auburn, International Center for Aquaculture and Aquatic Environments, Auburn University.

Quinn, T.P.; M.D. Adkison \& M.B. Ward. 1996. Behavioral tactics of male Sockeye salmon (Oncorhynchus nerka) under varying operational sex ratios. Ethology 102 (2): 304-322. doi: 10.1111/j.1439-0310.1996.tb01127.x.

SAKAKURA, Y. \& K. TSUKamoto. 1997. Effects of water temperature and light intensity on aggressive behavior in the juvenile yellowtails. Fisheries Science 63 (1): 42-45.

Sloman, K.A.; A.C. Taylor; N.B. Metcalfe \& K.M. Gilmour. 2001. Effects of an environmental perturbation on the social behaviour and physiological function of brown trout. Animal Behaviour 61 (2): 325-333. doi:10.1006/anbe.2000.1567.

SNedDon, L.U. \& J. Yerbury. 2004. Differences in response to hypoxia in the three-spined stickleback from lotic and lentic localities: dominance and an anaerobic metabolite. Journal of Fish Biology 64 (3): 799-804. doi:10.1111/j.10958649.2004.00361.x.

Sneddon, L.U.; S. Hawkesworth; V.A. Braithwaite \& J. Yerbury. 2006. Impact of environmental disturbance on the stability and benefits of individual status within dominance hierarchies. Ethology 112 (5): 437-447. doi:10.1111/j.14390310.2005.01192.x.

Valdimarsson, S.K. \& N.B. Metcalfe. 2001. Is the level of aggression and dispersion in territorial fish dependent on light intensity? Animal Behaviour 61 (6): 1143-1149. doi:10.1006/anbe.2001.1710.

Volpato, G.L. \& R.E. Barreto. 2001. Environmental blue light prevents stress in Nile tilapia. Brazilian Journal of Medical and Biological Research 34 (8): 1041-1045. doi:10.1590/ S0100-879X2004000400004.

WingField, J.C. 2003. Control of behavioural strategies for capricious environments. Animal Behaviour 66 (5): $807-$ 816. doi:10.1006/anbe.2003.2298.

ZAR, J. 1999. Biostatistical analyses. New Jersey, Printice Hall.

ZAYAN, R. 1991. The specificity of social stress. Behavioural Processes 25 (2-3): 81-93. doi:10.1016/0376-6357(91)90011-N.

Submitted: 07.XI.2011; Accepted: 21.I.2013.

Editorial responsibility: Lorenzo R.S. Zanette 